\title{
A COERÊNCIA ESTÉTICA COMO TEORIA DE VERDADE
}

\section{The aesthetic coherence as a truth theory}

\section{Cleverson Leite Bastos}

Doutor em Semiótica pela PUC-SP, Brasil. Professor do Programa de Pós Graduação da Pontifícia Universidade Católica do Paraná. Curitiba, PR - Brasil, e-mail: mestrado.filosofia@pucpr.br

\section{Resumo}

Dentre tantas teorias, teóricos e critérios pra determinar o que é verdadeiro, um, em especial, chama a atenção: a beleza (Pulchrum) nas teorias da física. Esse é justamente o título de um dos capítulos de Sonhos de uma teoria final, ${ }^{1}$ livro, na verdade um relatório de pesquisa, de Steven Weinberg, prêmio Nobel de física, 1979, pelo trabalho de unificação de duas das chamadas Forças Fundamentais da Natureza.

Palavras-chave: Beleza; Simetria; Simplicidade; Rigidez; Verdade; Critério.

\begin{abstract}
Among many theories, facts and criteria to determine what it is true, one, in special, calls attention: the beauty (Pulchrum), in the physics theories. This is actually the title of one of the chapters of Dreams of the final theory, book, a research to be more specific, of Steven Weinberg, Nobel prize winner of physics, 1979, for the work that united the two calling Fundamental Forces of Nature.
\end{abstract}

Keywords: Beauty; Symmetry; Simplicity; Stiffness; Truth; Criteria.

WEINBERG, Steven. Sonhos de uma teoria final: a busca das leis fundamentais da natureza. Rio de Janeiro: Rocco, 1996. p. 108-132. 


\section{Introdução}

Em uma rápida consulta a dicionários e enciclopédias especializadas em filosofia, epistemologia e lógica, é surpreendente o número de teorias sobre a verdade e seus critérios que podemos encontrar. O que faremos a seguir é elencar tais teorias e alguns dos critérios de verdade para dentre elas destacarmos a que nos interesse neste artigo.

a) como correspondência ou adequação: é a concepção que vem de Aristóteles, passando pela Idade Média e filosofia moderna, até ser encampada pela lógica contemporânea nas teorias de: Teoria Semântica de Tarski; Teoria da Congruência de Russell; Teoria da Correlação de Austin; Fisicalismo de Carnap; Teoria da Redundância de Ramsey; Teoria da Redundância de Willians, Teoria da Consistência de Quine;

b) como revelação, manifestação ou descoberta: como revelação Empirista das escolas Cirenáica, Epicurista e Estoica, até o conhecimento intuitivo de Ockham; como manifestação metafísica ou teológica: de Agostinho, passando por Descartes até Hegel, e por fim, como descoberta existencial: fenomenologia analítica, em especial Heidegger;

c) como dupla verdade: Averróis, Ockham, João de Jandum e Pompanazzi;

d) como conformidade a uma regra ou conceito: o pensamento fundado em leis formais, de modo geral o Idealismo, desde Platão, Agostinho, passando por Kant e a Escola de Baden até Hegel;

e) como coerência: o significado do "todo" é "tudo", de Spinoza, Bradley e Husserl a Frege e Bérgson;

f) como utilidade: vitalista, Nietzsche; pragmática, James, Schiller e Peirce; instrumental, Dewey;

g) como justificação: o programa de Davidson; a Teoria do Significa de Dummett; e a retórica de Perelman;

h) como consenso: Agir Comunicativo de Habermas;

j) como coerência estética: Kaku, Greene e Weinberg.

Neste artigo, nos deteremos em Weinberg. Ele faz parte de um seleto grupo de físicos-matemáticos, pesquisadores da Teoria das Cordas. Nesta teoria, as propriedades observadas de cada partícula elementar existem porque 
sua corda interna experimenta um determinado padrão vibratório ressonante. A perspectiva, aqui, difere daquela que os físicos advogavam anteriormente: as partículas fundamentais, na teoria anterior, eram explicadas ou descritas por diferenças estruturais. Embora "elementares", cada partícula é entendida como feita de um tipo diferente de "material". O "material" do elétron tinha carga negativa, o "material" do neutrino, por exemplo, não possuía carga elétrica.

A teoria das cordas altera essa visão, já patrimônio do ensino em física, declarando que o "material" e todas as manifestações da "matéria" e das "forças" é o mesmo: uma corda única e, eis aqui a dificuldade de visualizar, todas as cordas são absolutamente idênticas. Como diferenciar as partículas? Assim como em um violino, uma única corda pode ditar notas diferentes, as diferenças entre as partículas resultam de que suas respectivas cordas exprimem padrões ressonantes diferentes. Na nova perspectiva, o que era percebido como "partículas elementares" diferentes são, na verdade, "notas" diferentes de uma mesma corda fundamental.

Nesse caso, a intuição de Pitágoras é correta. O universo assemelhase a uma sinfonia cósmica porque é composto de um número indefinido de cordas vibrantes. A intuição unificadora de Pitágoras é correta porque a teoria das cordas nos oferece uma metáfora também unificadora:

Todas as partículas de matéria e todos os transmissores de força consistem de uma corda cujo padrão vibratório é a sua impressão digital. Como todos os acontecimentos físicos, processos de ocorrências do universo podem ser descritos em seu nível mais elementar em termos da ação de forças entre os componentes materiais e elementares, a teoria das cordas mantém a promessa de uma descrição unificada, única e completa do universo físico: uma teoria sobre tudo. (GREENE, 2001, p. 166-167).

Pesquisadores da Teoria das Cordas (GREENE, 2005), assim como Weinberg acreditam que ela é capaz de descrever e unificar todas as forças da natureza por um único esquema e assim fechar o fosso, existente desde início do século XX, entre "as leis do grande" (Einstein) e as "leis do pequeno" (Mecânica quântica). Por isso, a teoria das cordas que busca unificar as forças fundamentais, forte, fraca, eletromagnética e gravitacional, também é conhecida como Teoria do Tudo, Teoria Final, Teoria M ou, como Einstein a chamava, Teoria de Campo Unificado.

$\mathrm{Na}$ descrição de estados e forças os teóricos lançam mão de conceitos e princípios tais como simetria, supersimetria, riqueza, elegância, complexidade e beleza, objeto deste artigo. 
Algumas consequências da teoria das cordas, não absorvidas pelo senso comum, dizem respeito a dois campos básicos de investigação, a saber, em geometria quântica: hiperespaço (espaço $n$-dimensões), dimensões recurvadas, superpartículas, "cordas" e, em cosmologia (modelo-padrão da cosmologia): buracos negros, inflação, multiverso...

\section{A beleza como critério de verdade}

Segundo Weinberg a beleza é, de fato, um bom guia para as teorias físicas em direção a uma Teoria do Tudo (TT), contudo, o que significaria dizer que uma teoria é bonita ou elegante em física ou para um físico?

Outras questões vão surgindo quando pretendemos entender o sentido dos adjetivos bonita ou elegante atribuídos às teorias físicas. Vejamos algumas delas: O que é de fato uma teoria bonita? Que características de uma teoria física nos dão o senso de beleza? Por que e quando o senso de beleza dos físicos funciona? Como algo, quase sobrenatural como senso de beleza, ajuda não só a inventar, mas também a julgar a validade das teorias em física? O que, afinal, desejam os físicos atingir com suas teorias?

Para responder a essas questões não é adequado partir de uma definição a priori de beleza por duas razões. A primeira, e a mais óbvia, é que uma definição a priori, acadêmica, rogaria as questões, isto é, incorreria em petição de principio; a segunda, não tão óbvia, portanto menos ou nada consensual, é o que as pessoas estão dispostas a admitir como senso estético, juízo estético, e está ligado a uma expressão pessoal de prazer estético. Justamente por essa segunda razão, a menos consensual, que relacionar conceitos como beleza e física pode receber um juízo condenatório ou, no mínimo, uma advertência.

Em lugar disso, acompanharemos Weinberg em sua definição de beleza como critério de verdade em física.

\section{Percepção estética e certeza}

Para dar conta disso, já que não é permitido lançar mão de uma definição de beleza como ponto de partida, partindo de uma espécie de estética negativa, Weinberg nos convida a entender o que a beleza não é. 
Assim, a beleza, conceito pressuposto na constituição da verdade de teorias físicas, não pode ser entendida como: a) beleza mecânica, como simples arranjo formal de símbolos; b) elegância matemática ou física que é uma qualidade da demonstração, associada ao fácil e ao difícil, e não da teoria propriamente dita que é indiferente ao fácil e ao difícil: "elegância é para alfaiates".2

No entanto, a exegese da estética negativa nos revela que há três elementos na percepção de caráter estético que são equivalentes ao termo beleza: simplicidade, inevitabilidade e simetria.

Simplicidade: a simplicidade, não-mecânica, é uma das notas do que Weinberg quer denominar com o que ele chama de beleza:

Ambas as teorias da gravitação de Newton envolvem equações que nos dão as forças gravitacionais produzidas por uma dada quantidade de matéria. Na teoria de Newton, existem três destas equações (correspondendo às três dimensões do espaço) - na teoria de Einstein existem 14 por si só isso não pode ser considerado uma vantagem estética da teoria de Newton sobre a de Einstein. E, de fato, há muito mais beleza na teoria de Einstein, em parte por causa da simplicidade de sua idéia central sobre a equivalência de inércia e gravitação. Esse é o julgamento com o qual cientista geralmente tem concordado e, [...], foi grandemente responsável pela rápida aceitação da teoria de Einstein. (WEINBERG, 1996, p. 110).

\section{Inevitabilidade}

O senso de inevitabilidade, o necessitarismo, com que uma conclusão se impõe a partir dos postulados de uma teoria é outro dos atributos que podem designar uma teoria como "bela". O prazer estético brota da percepção de que em um trabalho musical ou uma pintura está completo e que nada, nenhuma nota, nenhum traço a mais, poderia ser acrescentado sem que o todo se desfizesse. Segundo Weinberg, esse critério é parcialmente verdadeiro e também pode ser estendido à Teoria da Relatividade Geral.

Uma vez conhecendo os princípios gerais da física dotados por Einstein, entende-se que não existe outra teoria da gravitação significativamente diferente à qual Einstein poderia ter sido levado. Como ele disse sobre a

2 SZILARD apud WEINBERG, Steven. Sonho de uma teoria final: a busca das leis fundamentais da natureza. Rio de Janeiro: Rocco, 1996. p. 109. 
relatividade geral: a atração principal da teoria está na sua completude lógica. Se uma única das conclusões concebidas a partir dela se mostrar errada, deve-se desistir dela; modificá-la sem destruir sua estrutura parece ser impossível. [...] Assim as 14 equações de Einstein possuem uma inevitabilidade, portanto, beleza ausentes nas três equações de Newton. Acho que era isso que Einstein queria dizer quando se referia ao lado das equações que envolvem o campo gravitacional em sua teoria da relatividade geral como belo como se fosse de mármore, em contraste com o outro lado das equações, que se referia a matéria, que lhe dizia ainda ser feio como se feito de madeira. A maneira como o campo gravitacional entra nas equações de Einstein é quase inevitável mas nada na relatividade geral explica porque a matéria toma a forma que tem. (WEINBERG, 1996, p. 110-111).

\section{Simetria}

Se simplicidade e inevitabilidade são tomados como conceitos, simetrias são tomadas como princípios. Por definição "um princípio de simetria nada mais é do que uma afirmação de que algo se apresenta da mesma forma quando olhado de pontos de vista diferentes" (WEINBERG, 1996, p. 111). Há muitos graus no que se pode admitir como simétrico, desde rostos, passando por formas geométricas até o espaço tido como vazio. Há simetrias não só de coisas como também há, e aqui reside o interesse da ciência, simetria de leis. Simetrias nas leis são princípios de invariância. Por definição, uma simetria nas leis da natureza reside em que, ao fazermos certas modificações a partir do ponto de vista do qual os fenômenos são observados, as leis não se alteram: as leis possuem sempre a mesma formulação independente de como as coordenadas são tomadas. Não faz diferença em que lugar do planeta a experiência foi realizada ou se foi realizada fora da galáxia. Também não importa o modo como datamos os eventos se, conforme um relógio ou o Big Bang, leis diferentes em tempos diferentes, em lugares diferentes são sempre as mesmas.

Se essas simetrias das leis da natureza são importantes na física clássica, sua importância é ainda maior na mecânica quântica. Pense: o que faz um elétron diferente do outro? Somente sua energia, seu momento e seu spin; além dessa propriedade todos os elétrons do universo são iguais. Todas essas propriedades de um elétron são apenas quantidades que caracterizam a maneira como a função de onda da quântica do elétron responde a transformações de simetrias: mudando a maneira como 
acertamos nossos relógios ou a localização e orientação de nosso laboratório. A matéria, portanto, perde seu papel central na física: tudo que resta são princípios de simetrias e as várias maneiras que as funções de ondas podem se comportar sob transformações de simetrias. (WEINBERB, 1996, p. 112).

A simetria das leis é um pressuposto fundamental da mecânica clássica e quântica. As propriedades de um elétron, sua energia, seu momento e seu spin, em todos os elétrons do universo são iguais: são quantidades que caracterizam a maneira como, por exemplo, uma função de onda quântica do elétron responde às transformações de simetrias, independente das coordenadas de tempo e espaço. O que importa é o modo como as funções de onda se comportam sob as transformações de simetrias.

Em velocidades constantes diferentes, também existem simetrias no espaço-tempo. Não importa se os observadores fazem suas experiências no sistema solar, no centro da galáxia, ou em uma galáxia distante, a milhares de quilômetros por segundo. O que fica estabelecido, menos óbvio que as translações ou rotações, é a simetria conhecida como "princípio de relatividade" de Einstein, 1905.

$\mathrm{Na}$ especialidade de Weinberg, a simetria subjacente à teoria eletrofraca é, segundo ele, mais esotérica: as mudanças não se dão segundo "o" nosso ponto de vista no espaço e no tempo. Mas sim "em" nosso ponto de vista sobre a identidade de diferentes tipos de partículas elementares.

Da mesma forma que é possível para uma partícula estar num estado quântico no qual não se encontra definitivamente nem aqui nem lá ou girando sem que esteja definitivamente no sentido horário ou anti-horário, pelas mesmas maravilhas da mecânica quântica também é possível termos uma partícula em um estado no qual ela não é definitivamente nem um elétron nem um neutrino, até que façamos uma medida de algumas propriedade que possam distinguir as duas como carga elétrica. [...] Simetrias do tipo subjacente a teoria eletrofraca são chamadas de Simetrias internas, porque podemos pensá-las como sendo relacionadas à natureza intrínseca das partículas, em vez de ser relacionadas as suas posições ou movimentos. (WEINBERG, 1996, p. 117).

São os princípios de simetria que dão às teorias um tipo feliz de rigidez. Rigidez entendida como um "quê" de universal que baliza os fenômenos no universo. Não é possível elaborar uma teoria capaz de descrever todas as forças de todas as partículas imagináveis na natureza. O que de fato precisamos 
é de uma teoria, respeitando Ockham, que descreva de forma universal todas e somente aquelas forças que realmente existem: gravitacionais, eletrofracas e fortes. É a esta rigidez que deve fazer parte de uma teoria física que Weinberg reconhece como beleza.

Se substituirmos feliz, em "teorias de um tipo feliz", por beleza, então poderemos entender que a beleza que Weinberg atribui às teorias físicas é semelhante pela apreensão de simplicidade, senso de inevitabilidade e simetria a alguns trabalhos de arte.

Assim como na arte, também em uma teoria podemos apreender ou sentir que não é possível trocar uma só nota, pincelada ou equação. A sensação de inevitabilidade é uma questão de gosto, de experiência estética, que não pode ser traduzida por uma forma lógica. A linha divisória entre "teoria elegante" e "lista de informações", se, por um lado não pode ser definida claramente, por outro, a inevitabilidade de sua "simplicidade" e "rigidez" deve ser vislumbrante para que a teoria possa ser levada a sério. Não é só a verdade e a validade que se busca em uma explicação científica, mas a elegância, a beleza da teoria, é parte do que se quer dizer com ela.

\section{Beleza "TIPO"}

Os parágrafos e citações anteriores demonstraram, ou pelo menos esta foi a nossa intenção, que, segundo Weinberg, os elementos conceituais exigidos para aceitação de uma teoria como verdadeira em física são, também, os mesmos que entram na percepção e no juízo de prazer estético. Embora o ideal de beleza esteja no infinito, sua realização, tanto no campo da arte como no campo da ciência, é limitada. Limitada pela definição que dela possamos dar. A beleza é: "até onde consigo traduzir em palavras, a beleza da simplicidade e da inevitabilidade - a beleza de uma estrutura perfeita de tudo se encaixando, de rigidez lógica, de nada ser alterável" (WEINBERG, 1996, p. 120).

A definição alcançada é importante porque impõe algumas restrições na comparação das estruturas das teorias físicas com a arte. A primeira é que as "teorias são muito esotéricas e devem ser assim, porque somos levados a desenvolvê-las usando uma linguagem, a da matemática, que não se tornou parte das ferramentas usuais do público instruído" (WEINBERG, 1996, p. 121). A segunda é que o teórico não é tão livre quanto o artista. Os princípios matemáticos não estão pré-ordenados e, por isso, construir ou criar uma teoria não é uma pura questão de dedução mecânica. Os princípios devem ser 
inventados durante a pesquisa e a dedução das consequências de um conjunto de princípios, escolhidos como rígidos, podem ser muito angustiantes, difíceis e não podem ser ensinados.

A terceira, e a mais intrigante, é que a beleza da estrutura sobrevive à morte dos princípios e da própria teoria:

Estranhamente, apesar da beleza das teorias físicas estar concretizada em estruturas matemáticas rígidas, baseadas em princípios subjacentes simples, as estruturas que possuem esse tipo de beleza tendem a sobreviver mesmo quando os princípios subjacentes se mostram errados. (WEINBERG, 1996, p. 121).

Assim, como exemplo, a matemática da teoria de Dirac sobrevive como uma parte essencial da teoria quântica de campos, embora o ponto de Dirac esteja errado. A estrutura formal da teoria de Dirac sobreviveu. É este estranho tipo de imortalidade que estruturas matemáticas e princípios físicos possuem, migrando como fantasmas de uma ambiente conceitual para outro e, como nas adaptações biológicas, mutando em outros corpos. A beleza sobrevive mesmo que os princípios da teoria sejam refutados.

\section{Considerações finais}

Há, finalizando, três razões pelas quais o senso de beleza é considerado critério de validade para as teorias físicas. A primeira faz apelo ao Princípio de Seleção Natural que, aplicado às ideias, nos indica que, através de uma série de eventos acidentais, de átomos até formas primitivas, de protozoários a peixes e pessoas, também o modo de olhar o universo se desenvolve por seleção natural: seleção natural de ideias através de falsos começos até alcançar uma forma que pode ser admitida como bela.

A segunda é porque somos capazes de escolha, porque se "esperamos que as teorias científicas bem-sucedidas sejam bonitas é simplesmente porque os cientistas tendem a escolher problemas que pareçam ter belas soluções" (WEINBERG, 1996, p. 128).

A terceira é porque "acreditamos" que iremos encontrar alguns princípios de beleza inevitável. Para nós também a beleza das teorias atuais é uma antecipação, uma premonição, da beleza da teoria final. E de qualquer maneira não podemos aceitar qualquer teoria como final, a menos que ela seja bonita (WEINBERG, 1996, p. 131-32). 


\section{Referências}

GREENE, B. O universo elegante: super-cordas, dimensões ocultas, e a busca da teoria definitiva. São Paulo: Companhia das Letras, 2001.

O tecido do cosmos: espaço, tempo e a textura da realidade. São Paulo: Companhia das Letras, 2005.

REES, M. Apenas seis números: as forças profundas que controlam o universo. Rio de Janeiro: Rocco, 2000.

WEINBERG, S. Sonho de uma teoria final: a busca das leis fundamentais da natureza. Rio de Janeiro: Rocco, 1996.

Recebido: 28/04/2008

Received: 04/28/2008

Aprovado: 27/05/2008

Approved: 05/27/2008 